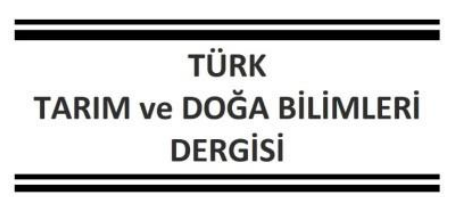

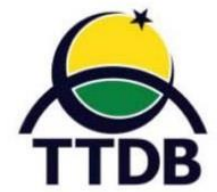

www.dergipark.gov.tr/turkjans

Araştırma Makalesi

\title{
Erzurum Olur Yöresinden Toplanan Berberis Vulgaris L. Meyvelerinin Antioksidan Aktivitelerinin Belirlenmesi
}

\author{
Fatma ERGÜN* \\ Kırşehir Ahi Evran Üniversitesi, Sağlık Bilimleri Fakültesi, Kırşehir, Türkiye \\ *Sorumlu Yazar: fatma.ergun@ahievran.edu.tr
}

Geliş Tarihi: 07.06.2021 Düzeltme Geliş Tarihi: 05.10.2021 Kabul Tarihi: 13.10.2021

Öz

Bu çalışma Berberis vulgaris L. meyve ekstraklarında toplam fenolik ve flavonoid madde miktarı ve antioksidan aktivitelerinin belirlenmesi amacıyla yapılmıştır. Folin-Ciocalteu ve alüminyum nitrat yöntemleri kullanılarak toplam fenolik ve flavonoid madde miktarları belirlendi. Hekzan ve metanol ekstraktında fenolik madde miktarı sırasıly $33,64 \pm 1,86 \mathrm{mg} \mathrm{GAE} \mathrm{g}^{-1}$ ve $85,98 \pm 1,59 \mathrm{mg}$ of $\mathrm{GAE} \mathrm{g}^{-1}$, flavonoid madde miktarı ise $94,74 \pm 2,59 \mathrm{mg} \mathrm{KE} \mathrm{g}^{-1}$ ve $64,74 \pm 1,86 \mathrm{mg} \mathrm{KE} \mathrm{g}^{-1}$ olarak belirlendi. $\mathrm{DPPH} \bullet$ radikal giderme aktivitelerinin, fenolik madde miktarının çok olduğu metanol ekstraklarında, $\mathrm{Fe}^{3+}-\mathrm{Fe}^{2+}$ indirgeme kapasitesinin ise flavonoid madde miktarı fazla olan hekzan ekstraklarında daha yüksek olduğu belirlenmiştir. Bulduğumuz sonuçlara göre $B$. vulgaris'in gıda takviyesi ve doğal antioksidan kaynağı olarak değerlendirilebileceği kanaatine varılmıştır.

Anahtar kelimeler: Berberis vulgaris L., antioksidan, DPPH, FRAP

\section{Determination of Antioxidant Activities of Berberis Vulgaris L. Fruits Collected from Erzurum Olur Region}

\begin{abstract}
This study was carried out to determine the total amount of phenolic and flavonoid substances and antioxidant activities in Berberis vulgaris L. fruit extracts. Total phenolic and flavonoid substances were determined by using Folin-Ciocalteu and aluminum nitrate methods. The amount of phenolic substance in the hexane and methanol extract was determined as $33.64 \pm 1.86 \mathrm{mg} \mathrm{GAE} \mathrm{g}^{-1}$ and $85.98 \pm 1.59 \mathrm{mg}$ of GAE g ${ }^{-1}$ respectively, and the amount of flavonoid substance was determined as $94.74 \pm 2.59 \mathrm{mg} \mathrm{QE} \mathrm{g}^{-1}$ and $64.74 \pm 1.86$ $\mathrm{mg} \mathrm{QE} \mathrm{g}^{-1}$ respectively. It was determined that $\mathrm{DPPH} \bullet$ radical scavenging activities were higher in methanol extracts with a high amount of phenolic substances, while the reducing capacity of $\mathrm{Fe}^{3+}-\mathrm{Fe}^{2+}$ was higher in hexane extracts with a higher amount of flavonoid substances. According to the results we found, it was concluded that $B$. vulgaris can be considered as a food supplement and a source of natural antioxidants.
\end{abstract}

Key words: Berberis vulgaris L., antioxidant, DPPH, FRAP

\section{Giriş}

Bitkiler yaşamsal faaliyetleri sırasında tokoferol, flavonoit, fenolik bileşik, alkaloit, klorofil, polifonksiyonlu organik asit ve karoten gibi birçok organik bileşik sentezlerler (Larson, 1988). Sekonder metabolit olarak tanımlanan fenolik bileşikler bitkilerde büyüme, çoğalma gibi yaşamsal faaliyetlerin yanı sıra zararlılarla mücadele ve dış etkilere karşı savunma görevinide üstlenmektedirler. Bitkilerdeki aroma ve koku özelliği de esansiyel yağ formundaki fenolik bileşik kaynaklıdır (Özkan ve Açıkgöz, 2007). Ayrıca bu bileşikler bitkinin antioksidan kapasitesinin belirlenmesinde oldukça önemlidir.

Antioksidanların kanser, kolesterol, diyabet ve yaşlılık kaynaklı hastalıklara karşı koruyucu etkiye sahip olduğu bildirilmiştir (Thangapazham ve ark., 2006; Erlund ve ark., 2008). Tahıl ve 
baklagiller, meyveler ve şifalı bitkiler başta olmak üzere birçok bitki türünde bol miktarlarda antioksidan bulunur (Foo ve Porter, 1981). Bitkilerin antioksidan kapasitesini belirleyen bu yapılar bitkilerin farklı kısımlarında değişik oranlarda bulunurlar. Ayrıca kırmızı ve siyaha yakın renge sahip meyvelerin antioksidan kapasiteleri daha yüksektir (Marja ve ark., 1999; Marianne ve Engelhart, 2002).

Pembe-kırmızı-siyah renkli meyve veren ve Berberidaceae familyasına ait olan yaklaşık 190 tür vardır (Meliani ve ark., 2011). Uzun çalı bitkisi yapısında olan türleri Türkiye ile beraber birçok ülkede doğal olarak yetişmektedir (Gundogdu,
2013). Bu türlere ait bitkiler büyük oranda fitokimyasal ve biyoaktif bileşen içerirler (Bakmohamadpor ve ark., 2021). Bu yapısal özellikleri nedeniyle birçok türü antibakteriyel, antikarsinojenik, antidiyabetik, antiinflamatuar, antihipertansif ve lipid düşürücü olarak kullanılmıştır. (Hadi ve ark., 2019). Ayrıca bazı türlerinin antiaritmik, antihistaminik, antikolinerjik ve yatıştırıcı etkilerinin de olduğunu gösteren çalışmalarda vardır (Shamsa ve ark., 1999). Bu familyaya ait türlerin İran'da geleneksel hekimlikte ve safra kesesinin yangısal bozukluklarının tedavisinde kullanıldığı bildirilmiştir (Zargari, 1983).

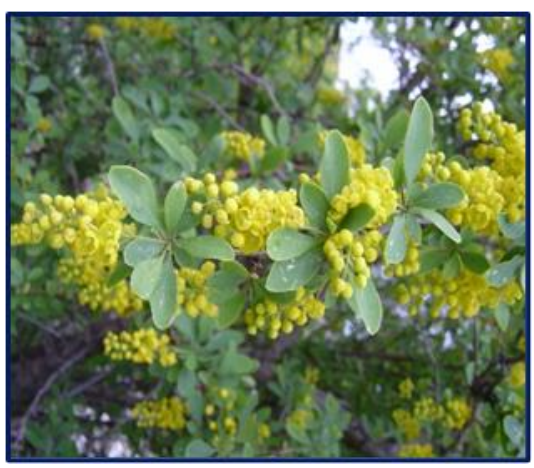

(Çiçek Formu)

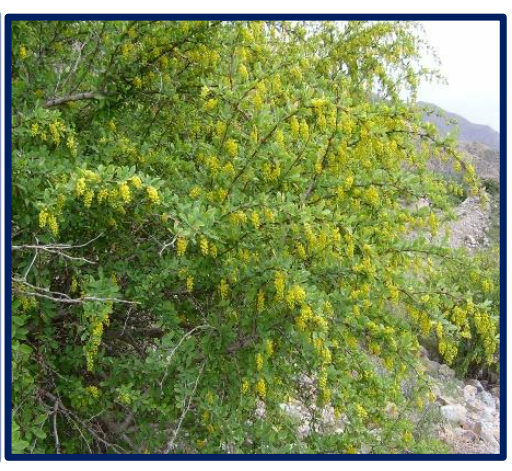

(BitkiFormu)

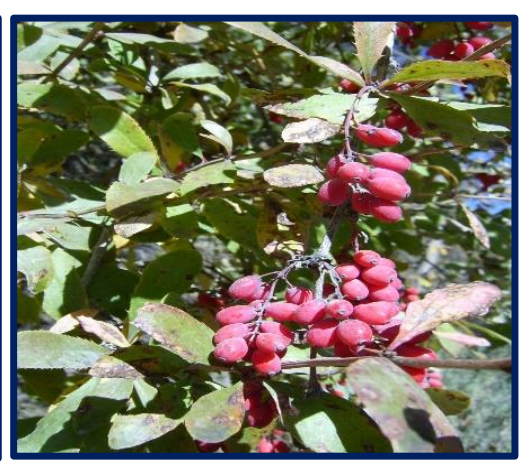

(MeyveFormu)

Şekil 1. Berberis vulgaris L. bitkisinin üç farklı formu

Berberis vulgaris L. Berberidaceae familyasına da yer alan önemli bir türdür. Ülkemizin Kuzey Anadolu Bölgesinde kendiliğinden yetişir. Nisan/Mayıs aylarında salkım şeklinde sarı çiçek açan, olgunlaştığında elips şeklinde kırmızı renkli meyve veren bu tür halk arasında kızamık, kadıntuzluğu, çoban tuzluğu olarak isimlendirilmektedir (Şekil 1). Bu türe ait meyveler vitamin $C$, malik asit ve tanen yönünden zengindir. Halk arasında iştah açıcı, ateş düşürücü ve bağışıklık sisteminin güçlendirilmesinde, kökleri ise doğal boya olarak kullanılmaktadır (Hanachi ve Golkho, 2009; Gundogdu, 2013). Yaprakları ve meyveleri ekşidir. Yöre halkı tarafından taze, kurutulmuş, reçel ve jöle şeklinde tüketilmektedir. Ayrıca gıda ürünü formülasyonlarında katkı maddesi olarak kullanıldığı da bildirilmiştir (Alavia ve Mazloumzadeh, 2012).

$\mathrm{Bu}$ çalışmada Erzurum ilinde doğal olarak yetişen Berberidaceae familyasına ait önemli bir tür olan $B$. vulgaris meyvelerinin biyoaktif bileşenlerini ve antioksidan kapasitelerini belirleyerek doğal antioksidan kaynağı olarak kullanılabilirliğinin araştırılması amaçlanmıştır.

\section{Materyal ve Metot Bitki Örneklerinin Toplanması}

$\mathrm{Bu}$ araştırmada kullanılan örnekler $40^{\circ} 49^{\prime} 26^{\prime \prime} \mathrm{N} \quad 42^{\circ} 05^{\prime} 31^{\prime \prime} \mathrm{E}$ (1565 m), 4049'20"N $42^{\circ} 06^{\prime} 16^{\prime \prime} \mathrm{E}$ (1542 m), koordinatlarında doğal ortamında kendiliğinden yetişmiş bitkilerden toplanmıştır. Toplanan meyve örnekleri destile su ile yıkanarak fiziksel kirliliklerden arındırıldı. $B$. vulgaris meyveleri gölgede kurutuldu ve kullanımına kadar $+4{ }^{\circ} \mathrm{C}^{\prime}$ de saklandı.

\section{B. vulgaris Meyve Ekstraklarının Hazırlanması}

B. vulgaris meyvesinin metanol ve hekzan ekstraklarını hazırlayabilmek için öncelikle $10 \mathrm{~g}$ kurutulmuş meyve örneği, öğütücüde öğütülüp ağzı kapalı erlene konuldu. Daha sonra üzerine numunenin yirmi katı çözücü $(200 \mathrm{~mL})$ ilave edilerek manyetik karıştırıcıda karıştırıldı. Elde edilen ekstreler süzüldü. Bu işlem ekstrelerin rengi açılıncaya kadar belirli aralıklarla tekrarlandı. Süzülmüş ekstreler birleştirildi. Bu işlemler hekzan ve metanol için ayrı ayrı yapıldı. Evaporatörde 45 ${ }^{\circ} \mathrm{C}$ 'de metanol ve $40{ }^{\circ} \mathrm{C}^{\prime}$ de hekzan uzaklaştırıldı. Ekstreler çalışmalar için $+4{ }^{\circ} \mathrm{C}^{\prime}$ de muhafaza edildi.

\section{Toplam Fenolik Madde Tayini}

Ekstraklarda toplam fenolik madde miktarı tayini Folin-Ciocaltaeu metoduna kullanılarak yapıldı (Slinkard ve Singleton, 1977). Öncelikle gallik asit kullanılarak standart grafik hazırlandı. 
Bitki metanol ve hekzan ekstraklarının 1000 ppm konsantrasyonda stok çözeltileri hazırlandı. Stok çözeltilerden $50 \mu \mathrm{L}$ alınarak distile su ile hacim $1840 \mu L^{\prime} y e$ tamamlandı. Karışıma $40 \mu \mathrm{L}$ FolinCiocalteu reaktifi (FCR) ilave edilerek 3 dakika oda sıcaklığında inkübe edildi. İnkübasyon sonrası \%2'lik (w/v) $\mathrm{Na}_{2} \mathrm{CO}_{3}$ çözeltisinden $120 \mu \mathrm{L}$ ilave edildi. Karışım 2 saat oda sıcaklığında bekletildikten sonra absorbansları 760 nm'de köre karşı ölçüldü. Ölçümler için 3 paralel çalışıldı. Ekstrakların toplam fenolik içerikleri gallik aside eşdeğer olarak belirlendi (mg GAE g ${ }^{-1}$ ).

\section{Toplam Flavonoid Madde Tayini}

Hekzan ve metanol ekstraklarının toplam flavonoid miktarları alüminyum nitrat metodu ile kuersetine eşdeğer olarak belirlendi (Moreno ve ark., 2000). Bu amaçla 1000 ppm'lik çözeltiler hazırlandı. Bu stok çözeltilerden $50 \mu \mathrm{L}$ alınarak hacimleri metanol ile $1920 \mu L^{\prime}$ ye tamamlandı. 40 $\mu \mathrm{L} 1 \mathrm{M}$ potasyum asetat eklendi ve bir dakika sonra $40 \mu \mathrm{L} \% 10^{\prime}$ luk alüminyum nitrat ilave edildi. 40 dakika inkübasyon süresinden sonra $415 \mathrm{~nm}$ 'de saf su ile hazırlanan köre karşı absorbansları ölçüldü. Ölçümler için 3 paralel çalışıldı. Ekstrakların toplam flavonoid içerikleri, kuersetine eşdeğer olarak belirlendi ( $\mathrm{mg} \mathrm{KE} \mathrm{g}^{-1}$ ).

\section{Serbest Radikal Giderme Aktivitesi (DPPH•) Tayini} Serbest radikal giderim aktivitelerinin belirlenmesi için Blois (1958) metodundan yararlanıldı. Serbest radikal olarak 1,1-Difenil-2pikrilhidrazil $(\mathrm{DPPH} \bullet)$ çözeltisi ve standart olarak ise 2,6-di-t-bütil-1-hidroksitoluen (BHT) kullanıldı. Meyve ekstraklarının ve standardın 1000 ppm'lik stok çözeltileri hazırlandı. Bu stok çözeltilerden 20, $40,60,80$ ve $100 \mu \mathrm{L}$ alınarak metanol ile hacimleri $400 \mu L^{\prime}$ ye tamamlandı. Daha sonra 0,1 mM DPPH• çözeltisinden $1600 \mu \mathrm{L}$ ilave edildi. Hazırlanan çözeltilerin oda sıcaklığında karanlıkta 30 dakika inkübe edildi. Daha sonra $517 \mathrm{~nm}$ 'de absorbans değişimleri metanole karşı ölçüldü. Azalan absorbanslar kalan serbest DPPH• çözeltisi miktarını, yani serbest radikal giderme aktivitesini verdi.
\% DPPH• radikali giderme aktivitesi aşağıda verilen formül ile hesaplandı:

$\% \mathrm{DPPH} \bullet$ radikali giderme aktivitesi $=\left[\left(\mathrm{A}_{0}-\mathrm{A}_{1}\right) /\right.$

$\left.A_{0}\right] \times 100$

$A_{0}$ : Kontrol reaksiyonunun absorbansı,

$A_{1}$ : meyve ekstreleri ve standart çözeltilerin absorbansı

\section{$\mathrm{Fe}^{3+}-\mathrm{Fe}^{2+}$ Kapasite Azaltma (FRAP) Gücü Tayini}

$\mathrm{Fe}^{3+}$ indirgeme gücü tayini Oyaizu (1986)'ya göre yapıldı. Standart olarak BHT kullanıldı. Öncelikle hekzan ve metanol ekstraklarından 1000 ppm'lik stok çözeltiler hazırlandı. Bu stok çözeltilerden konsantrasyon 1050 ? $\mathrm{mL}^{-1}$ olacak şekilde tüpe alındı. Üzerlerine toplam hacim $1,0 \mathrm{~mL}$ olacak şekilde saf su eklendi. Hazırlanan çözeltilerin üzerine 2,5'er $\mathrm{mL}$ fosfat tamponu $(0,2 \mathrm{M} \mathrm{pH} \mathrm{6,6)}$ ve potasyum ferrisiyanür (\%1'lik) çözeltisi ilave edilerek $50{ }^{\circ} \mathrm{C}$ 'de 20 dakika su banyosunda inkübe edildi. Daha sonra $2,5 \mathrm{~mL}$ $\% 10$ 'luk trikloroasetik asit (TCA) ilave edildi ve vortekslendi. Vortekslenen tüplerden alınan 2,5 $\mathrm{mL}$ 'lik örneklere $2,5 \mathrm{~mL}$ ultra saf su ve $0,5 \mathrm{~mL}$ demir (III) klorür (\% 0,1'lik) ilave edildi ve $700 \mathrm{~nm}$ 'de absorbans köre karşı okundu.

\section{Bulgular ve Tartışma}

Çalışmamızda kullandığımız $B$. vulgaris meyveleri Erzurum ilinin Olur bölgesindeki ormanlardan toplandı. Meyvelerden elde edilen ekstraklarda toplam fenolik ve flavonoid madde miktarı, DPPH $\bullet$ radikalini giderme aktivitesi ve $\mathrm{Fe}^{+3}$ indirgeme gücü kapasitesi belirlendi. Antioksidan aktiviteleri BHT standardı ile karşılaştırılarak sonuçlar yorumlandı.

B. vulgaris meyve ekstraklarında fenolik madde miktarlarının hesaplanmasında Gallik asit standart grafiğinden elde edilen $y=0,0456 x$ denklemi kullanıldı ve sonuçlar gallik aside eşdeğer olarak verildi. Benzer şekilde flavonoid madde miktarları alüminyum nitrat metoduyla, kuersetin standart grafiğinden elde edilen $y=0,035 x$ denklemi kullanılarak kuersetine eşdeğer olarak hesaplandı. Sonuçlar çizelge 1'de toplu olarak verildi.

Çizelge 1. B. vulgaris meyve ekstraklarının toplam fenolik ve flavonoid madde miktarları.

\begin{tabular}{|c|c|c|}
\hline Ekstraklar & $\begin{array}{l}\text { Fenolik madde miktarı } \\
\left(\mathrm{mg} \mathrm{GAE} \mathrm{g}^{-1}\right)\end{array}$ & $\begin{array}{l}\text { Flavonoid madde miktar } \\
\left(\mathrm{mg} \mathrm{KE}^{-1}\right)\end{array}$ \\
\hline B. vulgaris metanol ekstraktı & $85,98 \pm 1,59$ & $64,74 \pm 1,86$ \\
\hline B. vulgaris hekzan ekstraktı & $33,64 \pm 1,86$ & $94,74 \pm 2,59$ \\
\hline
\end{tabular}

Bulunan değerler 3 ölçümüm ortalamasıdır $(n=3) \pm$ standart sapma

Metanol ekstraklarında $85,98 \pm 1,59 \mathrm{mg} \mathrm{GAE}$ $\mathrm{g}^{-1}$ toplam fenolik madde belirlenirken flavonoid madde miktarı ise $64,74 \pm 1,86 \mathrm{mg} \mathrm{KE} \mathrm{g}^{-1}$ olarak hesaplandı. Hekzan ekstraklarında ise toplam 
fenolik ve flavonoid madde miktarları sırasıyla $33,64 \pm 1,86 \mathrm{mg} \mathrm{GAE} \mathrm{g}^{-1}$ ve $94,74 \pm 2,59 \mathrm{mg} \mathrm{KE} \mathrm{g}^{-1}$ olarak belirlendi. Sharifi ve Poorakbar (2015) Berberis integerrima meyvelerinde en yüksek

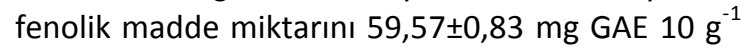
ve flavonoid miktarını ise $1,93 \pm 0,03 \mathrm{mg} \mathrm{KE} 10 \mathrm{~g}^{-1}$ olarak rapor etmişlerdir. $B$. integerrima meyvelerinde yapılan başka bir çalışmada ise fenolik madde miktarı 5036,38 $\pm 1465,28 \mathrm{mg} \mathrm{GAE} \mathrm{g}^{-1}$ ve flavonoid miktarı ise $3,55 \pm 1,80 \mathrm{mg} \mathrm{KE} \mathrm{g}^{-1}$ olarak belirlenmiştir (Falahi ve ark., 2019). Benzer bir çalışmada B. vulgaris meyvelerinde total fenolik madde miktarı 789,32 $\pm 88,50 \mathrm{mg} 100 \mathrm{~g}^{-1}$ taze meyve olarak rapor edilmiştir (Akbulut ve ark., 2009). Berberis asiatica meyvelerinin etanol ekstraklarında toplam fenolik madde miktarı,

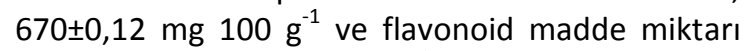
ise $190,40 \pm 0,52 \mathrm{mg} 100 \mathrm{~g}^{-1}$ olarak belirlenmiştir (Sarla ve ark., 2011). Ayrıca Berberis vulgaris ve Berberis crataegina meyvelerinin farklı çözücü ekstraklarında yapılan çalışmada ise toplam fenolik madde miktarı B. vulgaris meyvesinde $148 \pm 30,3$ $448,3 \pm 81,2 \mathrm{mg} \mathrm{GAE} \mathrm{mg}^{-1}$ aralığında, $B$. crataegina meyvelerinde $170,7 \pm 34,1-247 \pm 47,1 \mathrm{mg} \mathrm{GAE} \mathrm{mg}^{-1}$ aralığında bulunduğu rapor edilmiştir (Eroğlu ve ark., 2020). Bulduğumuz değerler ile rapor edilen bazı türlere ait değerlerle benzerlik göstersede, fenolik ve flavonoid madde miktarları, vejetasyon, hasat, iklim şartları, saklama koşulları gibi çevresel faktörlerden ve türler arası farklılıklardan etkilenmektedir.

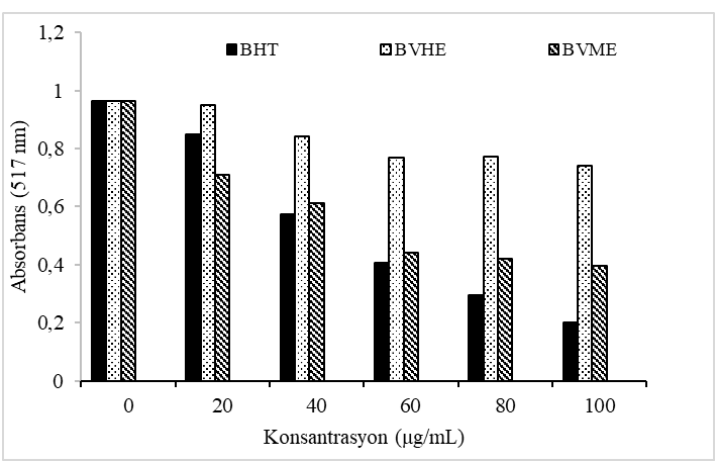

Şekil 2. B. vulgaris meyvelerinin metanol ve hekzan ekstraktlarının ve BHT'nin farklı konsantrasyonlarda $\mathrm{DPPH} \bullet$ serbest radikal süpürücü etkisi (BHT: Butillenmiş hidroksitoluen, BVHE: B. vulgaris hekzan ekstraktları, BVME: B. vulgaris metanol ekstraktları)

DPPH• (1,1-difenil 2-pikrilhidrazil) 517 $\mathrm{nm}$ 'de absorbans veren organik yapılı bir radikaldir. $\mathrm{DPPH} \bullet$ radikalinin $517 \mathrm{~nm}$ 'de absorbans azalması ölçülerek, kalan serbest DPPH• çözeltisi miktarı yani serbest radikal giderme aktivitesi belirlendi. Aktivite çalışmalarında standart olarak BHT kullanıldı.

Meyve ekstraklarının 20-100 $\mu \mathrm{g} \mathrm{mL}^{-1}$ aralığında, konsantrasyon artışına paralel olarak serbest radikal giderme aktivitelerinde artış olduğu görülmektedir (Şekil 2). $517 \mathrm{~nm}$ 'de absorbans azalması serbest radikal giderme aktivitesi fazla olduğunu işaret etmektedir. Ekstrakların ve standart maddenin DPPH• radikal giderme aktiviteleri hesaplandı (Çizelge 2). Yapılan antioksidan analizlerinde $100 \mu \mathrm{g} \mathrm{mL}^{-1}$ konsantrasyonunda DPPH • radikali giderme aktiviteleri karşılaştırıldığında, metanol ekstraktının aktivitesinin hekzan ekstrakt aktivitesinden daha fazla olduğu gözlendi.

Metanol ekstraktının radikal giderme aktivitesi BHT'ye oranla düşük olmasına rağmen, ortamda bulunan DPPH• radikalinin \%59,02'sini gidermiş olması oldukça yüksek aktiviteye sahip olduğunun göstergesidir. Yapılan benzer bir çalışmada DPPH• giderme yüzdeleri, \%68,33$\% 20,47$ aralığı ile $\% 74,72-\% 20,69$ aralığında olduğu bildirilmiştir (Hassanpour ve Alizadeh, 2016). Bu değerler bulduğumuz değerler ile benzerlik göstermektedir. Ayrıca Eroğlu ve ark. (2020)'nın iki tür üzerinde yaptıkları çalışmada ise DPPH• radikalini giderme yüzdelerinin, etanol ekstraklarında \%26,53-\%34,38 ve \%11,92-\%19,04 aralığında olduğunu belirtmişlerdir. Çalışmamızda özellikle metanol ekstraktında bulduğumuz değer bu değerlerden yüksektir.

$\mathrm{DPPH} \bullet \quad$ radikal gideriminin \%50'sinin inhibisyonunu sağlayan ekstrakt ve standart madde konsantrasyonu $\mathrm{IC}_{50}$ olarak belirlendi. $\mathrm{Bu}$ değer çalışılan konsantrasyonlara karşı \%DPPH• radikal giderme aktivite değerlerinin yerleştirilmesi ile elde edilen grafikler kullanılarak hesaplandı.

Çizelge 2. B. vulgaris meyve ekstraklarının ve BHT'nin DPPH• radikal giderme aktiviteleri (\%) (BHT: Butillenmiş hidroksitoluen, BVHE: B. vulgaris hekzan ekstraktları, BVME: B. vulgaris metanol ekstraktları).

\begin{tabular}{|c|c|c|c|c|c|}
\hline Numune ve Standart & $20 \mu \mathrm{g} \mathrm{mL}^{-1}$ & $40 \mu \mathrm{g} \mathrm{mL}^{-1}$ & $60 \mu \mathrm{g} \mathrm{mL}^{-1}$ & $80 \mu \mathrm{g} \mathrm{mL}^{-1}$ & $100 \mu \mathrm{g} \mathrm{mL}^{-1}$ \\
\hline BVHE & 5,6 & 12,15 & 20,12 & 19,91 & 23,42 \\
\hline BVME & 26,55 & 36,51 & 54,25 & 56,32 & 59,02 \\
\hline $\mathrm{BHT}$ & 11,92 & 40,45 & 57,98 & 69,79 & 81,14 \\
\hline
\end{tabular}


$\mathrm{IC}_{50}$ değeri ile DPPH• radikalini giderme aktivitesi arasında ters orantı olduğundan aktivite sıralaması BHT > BVME > BVHE şekildedir. Metanol ekstraktının \%50 inhibisyonu 68,18 $\mu \mathrm{g} \mathrm{\textrm {mL } ^ { - 1 }}$ konsantrasyonda, hekzan ekstraktının ise ancak 215,57 $\mu \mathrm{g} \mathrm{mL}^{-1 \text {, }}$ de sağladığı görülmektedir (Çizelge 3). Falahi ve ark. (2019) B. integerrima meyvelerinde yaptıkları çalışmada $I_{50}$ değerini

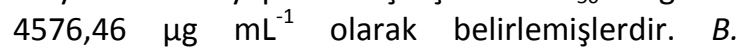
hispanica'da ise $I C_{50}$ değeri $0,210 \pm 0,017$ ile $0,180 \pm 0,020 \mathrm{mg} \mathrm{mL}^{-1}$ aralığında bulunmuştur (EI Fakir ve ark., 2021). Başka bir çalışmada etanol ve su ekstraklarında $\mathrm{IC}_{50}$ değerleri sırasıyla $0,658 \mathrm{mg}$ $\mathrm{mL}^{-1}$ ve $0,65 \mathrm{mg} \mathrm{mL}^{-1}$ olarak tespit edilmiştir (Motalleb ve ark., 2005).

Sonuçlar karşılaştırıldığında çalışmamızda metanol ekstraktının $I C_{50}$ değerinin düşük olduğu görülmektedir (Çizelge 3). Buda elde ettiğimiz ekstraktın oldukça yüksek aktiviteye sahip olduğunu gösterir.

$\mathrm{Bu}$ çalışmada $\mathrm{Fe}^{3+}$ indirgeme gücü FRAP metodu ile belirlendi. En önemli antioksidan mekanizmalarından biri olarak kabul edilen bu yöntemde antioksidan etki bir hidrojen atomunun verilmesi ve radikal zincirin kırılması prensibine dayanır. $\mathrm{Fe}^{3+}-\mathrm{Fe}^{2+}$ indirgeme kapasitesi ölçümlerinde $700 \mathrm{~nm}$ 'de absorbanslar belirlendi ve konsantrasyona karşı absorbans değerlerinin yerleştirilmesiyle grafik elde edildi (Şekil 3).

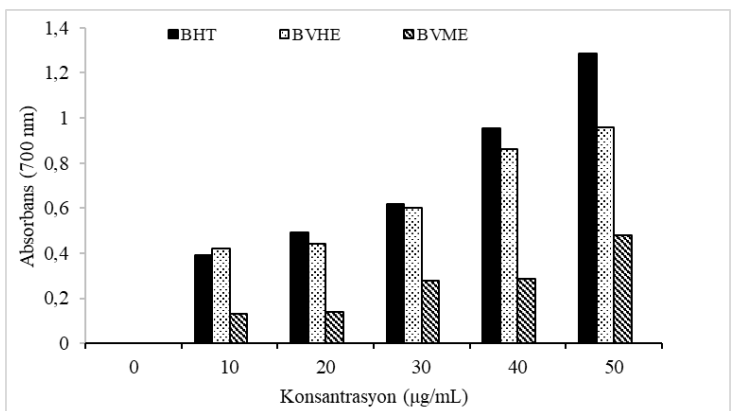

Şekil 3. B. vulgaris meyve ekstraktlarının $\mathrm{Fe}^{3+}-\mathrm{Fe}^{2+}$ indirgeme kapasitesinin BHT ile karşılaştırılması (10-50 $\mathrm{g} \mathrm{m} \mathrm{m}^{-1}$ ) (BHT: Butillenmiş hidroksitoluen, BVHE: B. vulgaris hekzan ekstraktı, BVME: $B$. vulgaris metanol ekstraktı).

Çizelge 3. B. vulgaris meyve ekstraklarının ve BHT'nin IC ${ }_{50}$ değerleri (BHT: Butillenmiş hidroksitoluen, BVHE: $B$. vulgaris hekzan ekstraktları, BVME: B. vulgaris metanol ekstraktları).

\begin{tabular}{lc}
\hline Ekstrakt ve Standart & $\mathrm{IC}_{\mathbf{5 0}}\left(\mu \mathbf{g ~ m L}^{-1}\right)$ \\
\hline BVHE & 215,57 \\
\hline BVME & 68,18 \\
\hline BHT & 57,31 \\
\hline
\end{tabular}

Grafikte artan absorbanslar indirgeme gücünü gösterir. B. vulgaris meyve ekstraklarında artan konsantrasyona paralel olarak indirgeme gücüde artmıştır. Fakat hekzan ekstraktındaki indirgeme yeteneği metanolden daha fazla ve standart olarak kullanılan BHT'nin değerlerine de oldukça yakındır. En yüksek konsantrasyonda (50

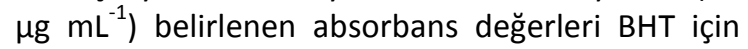
1,285, BVHE için 0,96 ve BVME için 0,48 olarak ölçülmüştür. Tespit edilen bu değerler $B$. vulgaris meyvelerinin $\mathrm{Fe}^{3+}$ indirgeme gücünün yüksek olduğunu göstermektedir. Berberidaceae familyasına ait $B$ integerrima (Moein ve ark., 2020) ve $B$. hispanica (El Fakir ve ark., 2021) türleri üzerinde yapılan çalışmalarda da yüksek indirgeme gücünün olduğu bildirilmiştir. Bu durum aynı familyaya ait türler arasındaki benzerliklerin olduğunu destekler tarzdadır.

\section{Sonuç}

B. vulgaris'in berberin başta olmak üzere alkoloid, flavonoid ve fenolik bileşenler içerdiği bildirilmiştir (Arslanoglu ve ark., 2019). Ayrıca türün antibakteriyel, antikarsinojenik, antidiyabetik, antiinflamatuar, gibi etkilerininde olduğu bilinmektedir. Doğal olarak yetişen meyvelerin biyoaktif madde miktarları ve antioksidan kapasiteleri, tespit yöntemi, tür farklılığı, yetişme ortamı, olgunluk derecesi, iklim koşulları ve rakım gibi birçok çevresel faktörden etkilenmektedir. B. vulgaris meyveleri ile yaptığımız çalışmada elde edilen sonuçlara göre, meyve ekstraktlarının bu familyaya ait diğer türlere benzer şekilde radikal giderme ve indirgeme gücü aktivitesinin oldukça yüksek olduğu tespit edilmiştir. Bu türün, doğal antioksidan kaynağı olarak yaygın kullanılabilmesi için toksisitesinin belirlenmesi amacıyla yeni çalışmalara ihtiyaç vardır.

Teşekkür: $\mathrm{Bu}$ çalışma Kırşehir Ahi Evran Üniversitesi Bilimsel Araştırma Projeleri Koordinasyon Birimi tarafından desteklenmiştir (Proje Numarası: SYO.A4.20.002). Kırşehir Ahi Evran Üniversitesi Bilimsel Araştırma Projeleri Koordinasyon Birimine ve makalede kullandığımız 
fotoğraflar için Sayın Ergin ERGÜN'e teşekkür ederiz.

\section{Kaynaklar}

Akbulut, M., Çalışır, S., Marakoglu, T., Çoklar, H. 2009. Some physicomechanical and nutritional properties of Berberis vulgaris $\mathrm{L}$. fruits. Journal of Food Process Engineering. 32: 479-511.

Alavia, N., Mazloumzadeh, S.M. 2012. Effect of harvesting and drying methods of seedless barberry on some fruit quality. J. Saudi Soc. Agric. Sci. 11: 51-55.

Arslanoglu, S.F., Ayna, O.F. 2019. Anadolu Cografyasında Yayılış Gösteren Berberis Türleri ve Geleneksel Kullanımı. International Journal of Life Sciences and Biotechnology. 2(1): 36-42.

Bakmohamadpor, M., Javadi A., AzadmardDamirchi, S., Jafarizadeh-Malmiri, H. 2021. Effect of barberry (Berberis vulgaris) fruit powder on the quality and shelf life stability of puffed corn extrude. NFS Journal, 22: 9-13.

Blois, M.S. 1958. Antioxidant determinations by the use of a stable free radical. Nature, 181:1199-1200.

El Fakir, L., Bouothmany, K., Alotaibi, A., Bourhia, M., Ullah, R., Zahoor, S., El Mzibri, M., Gmouh, S., Alaoui, T., Zaid, A., Benbacer, L. 2021. Antioxidant and understanding the anticancer properties in human prostate and breast cancer cell lines of chemically characterized methanol extract from Berberis hispanica Boiss. \& Reut. Appl. Sci. 11(8): 3510.

Erlund, I., Koli, R., Alfthan, G., Marniemi, J., Puukka, P., Mustonen, P., Mattila, P., Jula, A. 2008. Favorable effects of berry consumption on platelet function, blood pressure, and HDL cholesterol. The Am. J. of Clin. Nutrition. 87(2): 323-331.

Eroğlu, A.Y., Çakır, Ö., Sağdıç, M., Dertli E. 2020. Bioactive characteristics of wild Berberis vulgaris and Berberis crataegina fruits. Journal of Chemistry. Article ID 8908301.

Falahi, E., Ahmadvand, H., Moghadam, E.H., Roosta, S. 2019. Antioxidant properties of some traditional Iranian edible fruits growing wild in lorestan province in the western Iran. 4(2): 76-81.

Foo, L.Y., Porter, L.J., 1981. The structure of tannins of some edible fruits. Journal Science Food Agricaltural, 32: 711-716.

Gundogdu, M. 2013. Determination of antioxidant capacities and biochemical compounds of Berberis vulgaris L. Fruits. Advances in Environmental Biology, 7(2):344-348.
Hadi, A., Arab, A., Ghaedi, E., Rafie, N., Miraghajani, M., Kafeshani, M. 2019. Barberry (Berberis vulgaris L.) is a safe approach for management of lipid parameters: A systematic review and metaanalysis of randomized controlled trials. Complement. Ther. Med. 43: 117-124.

Hanachi, P., Golkho, S.H. 2009. Using HPLC to determination the composition and antioxidant activity of Berberis vulgaris. European Journal of Scientific Research. 29(1):47-54.

Hassanpour, H., Alizadeh, S. 2016. Evaluation of phenolic compound, antioxidant activities and antioxidant enzymes of barberry genotypes in Iran. Sci Hortic. 200: 125-130.

Larson, R.A. 1988. The antioxidants of higher plants. Phytochemistry. 27: 969-978.

Marianne, L., Engelhart, M.D. 2002. High Intakes of antioxidant vitamins $C$ and $E$ may lower the risk of alzheimer's disease. Journal of the American Medical Association 287 (24): 3223.

Marja, P.K., Hopia, A.I., Vuorela, H.J., Rauha, J.P., Pihlaja, K., Kajula T.S., Heinonen, M. 1999. Antioksidant Activity of plant extracts containing phenolic compounds. Journal of Agricultural and Food Chemistry (47): 39543962.

Meliani, N., Dib A.E.M., Allali H., Boufeldja T. 2011. Hypoglycaemic effect of Berberis vulgaris L. in normal and streptozotocin-induced diabetic rats, Asian Pacific Jor. of Tropical Biomedicine. 1(6): 468-471.

Moein, M., Sabahi, Z., Salim, H. 2020. A glance at Berberis integerimma pharmacological effects and its active constituents. Trends in Pharmaceutical Sciences. 6(1): 1-10.

Moreno, M.I.N., Isla, M.I., Sampietro, A.R. and Vattueno, M.A. 2000. Comparison of the free radical scavenging activity of propolis from several regions of Argentina. Journal of Ethnopharmacology, 71:109-114.

Motalleb, G., Hanachi, P., Kua, S.H., Fauziah, O., Asmah, R. 2005. Evaluation of phenolic content and total antioxidant activity in Berberis vulgaris fruit extract. Journal of Biological Sciences. 5(5): 648-653.

Oyaizu, M. 1986. Study on products of Browning reactions: antioxidative activities of products of browning reaction prepared from glucosamine. Jpn. J. Nutr. 44: 307-315.

Özkan K., Açıkgöz, Z. 2007. Kanatlı kümes hayvanlarının beslenmesi. 1.Baskı, Hasad Yayıncılık, İstanbul.

Sarla, S., Subhash, C., Alok, K.S. 2011. Berberis asiatica future based excellent fruit in nutritional profile, antimicrobial and 
antioxidant ingredients. International research journal of pharmacy. 2(12): 213-216.

Shamsa, F., Ahmadiani, A., Khosrokhavar, R. 1999. Antihistaminic and anticholinergic activity of barberry fruit (Berberis vulgaris) in the guinea-pig ileum. Journal of Ethnopharmacology. 64, 161-166.

Sharifi, F., Poorakbar, L. 2015. The survey of antioxidant properties of phenolic compounds in fresh and dry hybrid Barberry fruits (Berberis integerrimax vulgaris).
Cumhuriyet Science Journal. 36(3): 16091617.

Slinkard, K., Singleton, V.L. 1977. Total phenol analyses: Automation and comparison with manual methods. American Journal of Enology and Viticulture, 28:49-55.

Thangapazham, R.L., Sharma, A., Maheshwari, R.K. 2006. Multiple molecular targets in cancer chemoprevention by curcumin. The AAPS Journal. 8(3): 443.

Zargari, A. 1983. Medicinal Plants, Tehran University Press, Tehran 1,

68. 